\title{
Cycloheximide-producing and Fungicidin-producing Mutants of Streptomyces noursei
}

\author{
BY LIBUŠE DOLEŽILOVÁ, J. SPIŽEK, M. VONDRAČEK, \\ FRANTIŠKA PALEČKOVÁ AND Z. VANĚK \\ Institute of Microbiology, Czechoslovak Academy of Sciences, \\ Prague 4, Budèjovická 1083 and Antibiotics Research Institute, \\ Roztoky near Prague, Czechoslovakia
}

(Received 24, August 1964)

\begin{abstract}
SUMMARY
Streptomyces noursei strain 52/152 produced compounds of the cycloheximide series and fungicidin. On the contrary its mutant strain $54 / 465$ did not produce any compound of the cycloheximide series, and as compared with strain 52/152 produced about double the amount of fungicidin. This strain 52/152 was also insensitive to additions to the cultivation medium of fungicidin up to a concentration of $20,000 \mathrm{units} / \mathrm{ml}$. In the strains studied, a direct proportionality was observed between fungicidin production and sensitivity to it. The interrelation of their production is discussed from the viewpoint of a common precursor for fungicidin and cycloheximide (malonyl-coenzyme A).
\end{abstract}

\section{INTRODUCTION}

In a previous paper Spižek et al. (1965a) studied the influence of mutagenic agents (ultraviolet (u.v.) radiation, X-rays, nitrogen-mustard) on the incidence of biochemical mutants which showed qualitative changes in their pattern of production of secondary metabolites of Streptomyces noursei. Spižek et al. (1965b) showed that fungicidin production could to some extent be influenced by the addition of cycloheximide to the culture medium and conversely that the cycloheximide production could be influenced by additions of fungicidin. In the present paper quantitative correlations between fungicidin and cycloheximide production were studied in selected strains of $S$. noursei $(52 / 152,54 / 465,54 / 126)$ and also the sensitivity of these strains to added fungicidin in relation to changes in secondary metabolite production.

\section{METHODS}

Mutants 52/152 and 54/465 were industrial strains; mutant 54/126 was a nonproducer of cycloheximide and fungicidin. Mutants were isolated after treatment with u.v.-radiation, X-radiation and nitrogen mustard. Streptomyces noursei, no. 1475 by selection after treatment with u.v.-radiation, X-radiation and nitrogenmustard, yielded mutant 52/152; and 52/152 by further similar treatment yielded mutant 54/465, and by $X$-radiation only mutant 54/126. Ultraviolet irradiation was done with a germicidal lamp (type GE $30 \mathrm{~W}$ ) at working distance $30 \mathrm{~cm}$.; the time of irradiation (usually 15-30 sec.) was adjusted to yield $0.5-1 \%$ survival. X-ray irradiation (Machlett AEG-50T; $50 \mathrm{kV}$., $30 \mathrm{~mA}$., filter $0 \cdot 1 \mathrm{~mm}$. Al, 55.040 
r./min.) was done with doses $5 \times 10^{4} \mathrm{r}$. resulting in about $1 \%$ survival. Nitrogenmustard ( $N$-methyl- $\beta$-dichlorethylamine hydrochloride) was used at $0.01 \mathrm{~m}$ in $\mathrm{m} / 15$ phosphate buffer (pH 8); after $30 \mathrm{~min}$. treatment there was about $20 \%$ survival, and the action of the agent was interrupted by transferring the suspension of conidia to a decontaminating solution ( $1 \mathrm{~g}$. glycine, $1000 \mathrm{ml}$. distilled water). The suspensions of conidia $\left(10^{6}\right.$ total conidia/ml.) were mechanically rocked during treatment with mutagenic agents. Viable counts were checked by plating of conidia on cultivation agar medium.

The culture medium used had the following composition (in $\mathrm{g} . / 1000 \mathrm{ml}$.): glucose, 25; Bacto-Peptone, 2; yeast extract, $1 ; \mathrm{KH}_{2} \mathrm{PO}_{4}, 5 ; \mathrm{NaCl}, 0.5 ; \mathrm{MgSO}_{4} .7 \mathrm{H}_{2} \mathrm{O}, 0.5$; nucleic acid hydrolysate (from yeast nucleic acid), 3; nucleic acid hydrolysate (from thymus nucleic acid), 2; casein hydrolysate, 5; vitamin solution (Hopwood \& Sermonti, 1952), 0.1. The solutions of casein and nucleic acid hydrolysates and the vitamins solution were prepared according to Pontecorvo (1953).

Culture medium was distributed in $80 \mathrm{ml}$. volumes into $500 \mathrm{ml}$. conical flasks. The medium was sterilized at $125^{\circ}$ for 15 min.; final $\mathrm{pH}$ was $6 \cdot 8-7 \cdot 0$.

For inoculation, a conidial suspension $\left(10^{6}-10^{7}\right.$ conidia/flask) was used and the flasks were incubated for $168 \mathrm{hr}$ on a reciprocal shaker (98 strokes/min., length of stroke $10 \mathrm{~cm}$.).

The appearance of secondary metabolites other than fungicidin was followed by paper chromatography. Chloroform extracts of culture fluid, obtained by separating the mycelium on a centrifuge, were submitted to this analysis. The descending technique was used, on Schleicher-Schüll $2043 \mathrm{~b}$ paper with the solvent system of benzene + glacial acetic acid + water $(6+7+3$, by vol. $)$. The spots were detected by u.v. irradiation (254 $\mathrm{m} \mu$, Hanovia Chromatolight) and by the hydroxamate test.

Cycloheximide was assayed by the plate-diffusion method (Growe \& Randall, 1955) with Saccharomyces pastorianus no. 21-6-1 CHI sAs* as test organism. For

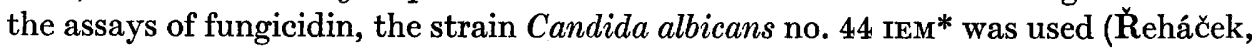
1958).

\section{RESULTS}

From the summarized chromatograms shown in Fig. 1 it can be seen that the culture fluid of Streptomyces noursei strain 52/152 contained actiphenol in addition to fungicidin and compounds of the cycloheximide series (i.e. cycloheximide, dehydrocycloheximide, anhydrocycloheximide). On the contrary, in strain 54/465 (which produced large amounts of fungicidin) the synthesis of compounds of the cycloheximide series was completely suppressed. This strain, however, did produce a compound with light greenish blue fluorescence, $R_{F} \mathbf{0 \cdot 8 3}$. Both strains also produced a compound of $R_{F}$ value $0 \cdot 70$, which showed a yellow fluorescence under u.v. radiation and had growth inhibitory activity against Bacillus subtilis 3366 FDA. It can also be seen from Fig. 1 that $S$. noursei strain 54/126 differed from the other strains examined by not producing any of these compounds. It did, however, produce a compound with a violet fluorescence and $\boldsymbol{R}_{F}$ value $\mathbf{0 \cdot 7 3}$. All three strains produced compounds of the dioxopiperazine type, i.e. 3-isobutylidene-6-benzylidene-2,5-dioxopiperazine $\left(R_{F} \quad 0 \cdot 40\right)$ and 3,6-dibenzylidene-2,5-dioxopiperazine $\left(R_{F} 0.93\right)$.

* Czechoslovak Collections of Micro-organisms. 
In view of our previous finding (Spižek et al. 1965b), that a close relationship exists between fungicidin and cycloheximide production, it appeared interesting to analyse the interrelation of the production of both antibiotics in the selected strains. It can be seen from Table 1 that fungicidin production by Streptomyces noursei strain 54/465 (which only produced fungicidin and no cycloheximide-type substances) was about twice as high as fungicidin production by the original strain $52 / 152$ which produced both fungicidin and compounds of the cycloheximide series.

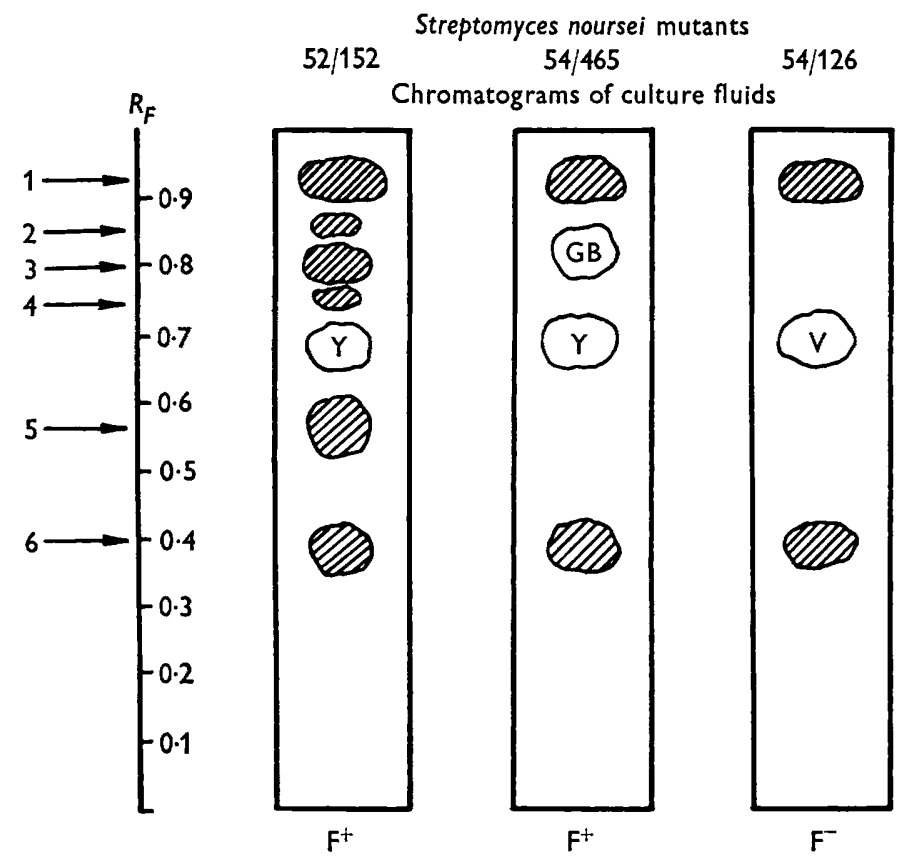

Fig. 1. Chromatographic spectra of products formed during cultivation of Streptomyces noursei mutants. V, violet fluorescence $\left(R_{F} 0 \cdot 72\right) ; \mathrm{Y}$, yellow fluorescence $\left(R_{F} 0 \cdot 70\right)$; GB, green-blue fluorescence $\left(R_{F} \mathbf{0} \cdot 83\right) ; \mathrm{F}^{+}$, presence or $\mathrm{F}^{-}$, absence, of producing capacity for fungicidin (microbiological plate assay). 1: 3,6-dibenzylidene-2,5-dioxopiperazine; 2: dehydrocycloheximide; 3 : actiphenol; 4: anhydrocycloheximide; 5: cycloheximide; 6: 3-isobutylidene-6-benzylidene-2,5-dioxopiperazine.

Table 1. Relation between capacity for fungicidin production by Streptomyces noursei mutants and resistance to fungicidin concentrations

Streptomyces
noursei
strain no.
$\mathbf{5 4 / 4 6 5}$
$\mathbf{5 2} / 152$
$\mathbf{5 4} / 126$

\begin{tabular}{|c|c|}
\hline \multicolumn{2}{|c|}{ Production of } \\
\hline $\begin{array}{l}\text { Fungicidin } \\
\text { (units/ml.) }\end{array}$ & $\begin{array}{c}\text { Cycloheximide } \\
(\mu \mathrm{g} . / \mathrm{ml} .)\end{array}$ \\
\hline 15,000 & $<0 \cdot 25$ \\
\hline 6,000 & 700 \\
\hline$<\mathbf{5}$ & $<0.25$ \\
\hline
\end{tabular}

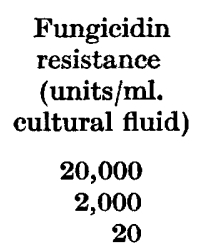

Data on sensitivity of the individual strains to fungicidin are summarized in Table 1. The high fungicidin producer strain $54 / 465$ was resistant to concentrations up to 20,000 units fungicidin $/ \mathrm{ml}$. culture fluid. Strain 52/152 was resistant only to concentrations below 2000 units fungicidin $/ \mathrm{ml}$. In contrast to this, the growth of the non-producer of fungicidin strain 54/126 was inhibited even by 20 units fungicidin $/ \mathrm{ml}$. 


\section{DISCUSSION}

In previous papers concerned with cycloheximide biosynthesis (Kharatyan et al. 1962; Vaněk, Půža, Cudlín \& Doležilová, 1964) it was pointed out that the cycloheximide ring system is built from malonate units (malonyl-coenzyme A). It is likewise evident from studies of fungicidin biogenesis (Rickards et al. 1964) that the lactone moiety of the fungicidin molecule is predominantly formed by condensation of malonate units. We consider it therefore very likely that in the case of our Streptomyces noursei mutant $\mathbf{5 4 / 4 6 5}$ the metabolic pathway leading to compounds

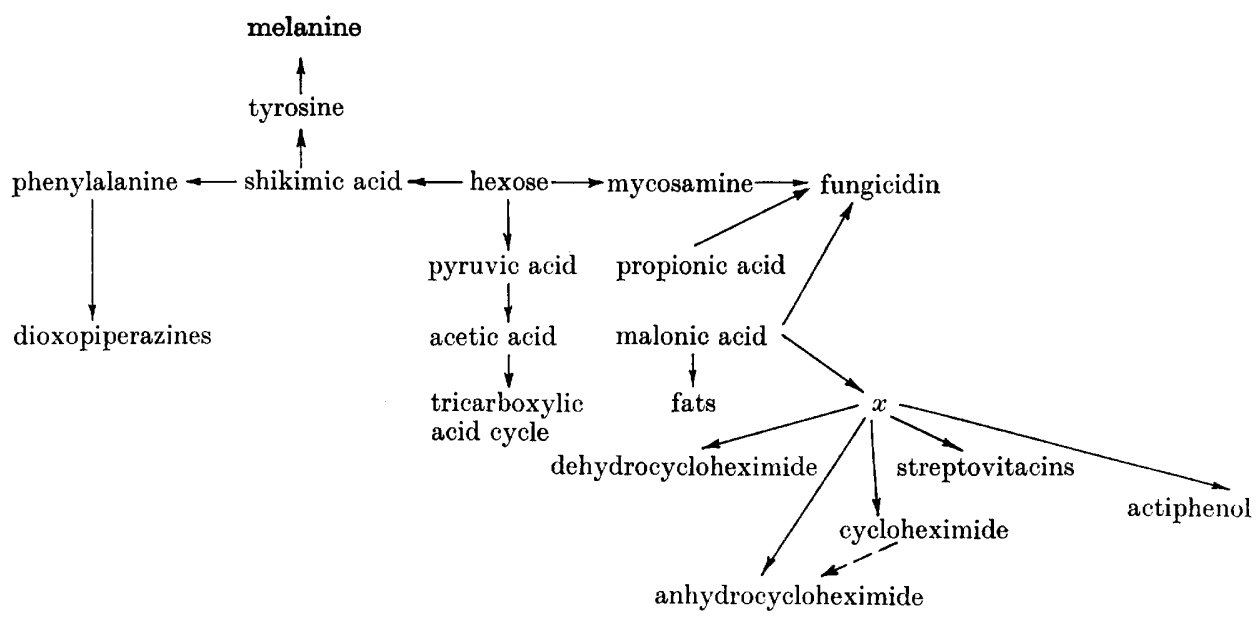

Fig. 2. Scheme of biosynthesis of secondary metabolites of Streptomyces noursei. Dotted arrow indicates a possible step not yet proved experimentally.

of the cycloheximide series is blocked, which results in preferential utilization of malonate units for the synthesis of fungicidin. Metabolic pathways leading to secondary metabolites produced by $S$. noursei are schematically shown in Fig. 2. Compounds of the dioxopiperazine type are not directly connected with the biosynthesis of fungicidin and cycloheximide. It follows from the work of Doležilová et al. (1965) that phenylalanine is the precursor of these substances (the shikimic acid pathway). When we consider the fact that among biochemical mutants obtained from $S$. noursei, strains can also be found which, while producing no compounds of the cycloheximide series (Spižek et al. 1965a), did produce fungicidin without showing any increased production capacity for it, we may assume that to obtain an increased ability to produce fungicidin, an additional hit may prove necessary to block a centre responsible for maintaining the high amounts of secondary metabolites produced. 


\section{REFERENCES}

Doležilová, L., Málek, I., Pokorná, L., Palečrová, F., Vondráček, M. \& Vaněk, Z. (1965). Metabolites of $S$. noursei. VIII. Study of biosynthesis of 3,6-dibenzylidene2,5dioxopiperazine in $S$. noursei by means of auxotroph mutants. Fol. microbiol (in the Press).

Growe, D. C. \& Randall, W. A. (1955). Assay Methods of Antibiotics, 1st ed. New York: Med. Encyclopedia.

Hopwood, D. A. \& Sermonti, G. (1962). The genetics of Streptomyces coelicolor. Adv. Genet. 11, 278.

Kharatyan, S., PƯža, M., Spížek, J., DoležIlová, L., VanĚK, Z., Vondráček, M. \& Rickards, R. W. (1962). Biogenesis of cycloheximide and related compounds. Chem. Ind. 25, 1038.

Ponteconvo, G. (1953). The genetics of Aspergillus nidulans. Adv. Genet. 5, 141.

REHÁČK, Z. (1958). Microbiological titration of antifungal antibiotics of a polyene type. Cs. Microbiol. 2, 128.

SpížEK, J., MÁleK, I., DoležILOVÁ, L., VoNDRÁČeK, M. \& VANĚK, Z. (1965a). Metabolites of $S$. noursei. IV. Study of secondary metabolites produced by $S$. noursei by means of biochemical mutants. Fol. microbiol (in the Press).

SpížEK, J., MáleK, I., SuchÝ, J., VondRÁČEK, M. \& VANĚK, Z. (1965b). Metabolites of S. noursei. V. Production of cycloheximide and actiphenol in relation to production of fungicidin. Fol. microbiol (in the Press).

Rickards, R. W., Birch, A. J., Holzapfel, C. W., DJerassi, C., Seidel, P. C., Suzuki, M., Westley, J., Dutcher, J. D. \& Thomas, R. (1964). Aspects of nystatin biosynthesis. Abstr. Antibiotica Congressus, Praga.

VANĚK, Z., PƯŽA, M., Cudlín, J. \& DoležIlová, L. (1964). Metabolites of S. noursei. III. Incorporation of ${ }^{14} \mathrm{C}$-carbon dioxide into cycloheximide. Biochem. biophys. Res. Comm. 5, 532. 